\title{
SPRAY RETENTION MODELS FOR VEGETABLE CROPS: PRELIMINARY INVESTIGATION
}

\author{
W.A. FORSTER, K.D. STEELE, R.E. GASKIN and J.A. ZABKIEWICZ \\ Plant Protection Chemistry ${ }_{N Z}$, Forest Research, PB 3020, Rotorua \\ Corresponding author: alison.forster@forestresearch.co.nz
}

\begin{abstract}
This study tests the most appropriate of three mathematical models for spray retention by plant foliage. The current study utilised two plant species, potato (easy to wet with relatively horizontal leaves) and onion (difficult to wet with relatively vertical foliage). Formulations providing a range of dynamic surface tensions $(26-73 \mathrm{mN} / \mathrm{m})$ were used at two nominal spray volumes (200 and 500 litres/ha). The model by Grayson et al. (1993) worked reasonably well with the current data. However, to be truly predictive, extensive revision is required and recommendations for this are outlined.
\end{abstract}

\section{INTRODUCTION}

Spray deposition is the amount of active ingredient (ai) or spray impacting the target area (i.e. application volume minus drift), whereas retention is the amount of solution (droplets and satellite droplets) remaining on the plant (i.e. retention is deposition minus run-off and droplet reflection). Spray retention is a consequence of many factors including dynamic interactions of formulants within the spray droplet during flight and on impact, physical properties of the droplet, leaf surface morphology and leaf orientation. There have been many studies of spray retention by plants, but only a few models of spray retention by arable and vegetable crops.

A model by Bache \& Uk (1975) and Bache $(1979,1985)$ is useful for discerning the way in which the vertical distribution pattern is likely to be influenced by droplet size, wind-speed and foliage area. A study by Gyldenkærne et al. (1999) modelled the ground deposit of pesticides in relation to cereal canopy and density. This study found that soil deposition, or pesticide capture by the canopy, may be calculated from a simple exponential expression including a pesticide coefficient and leaf area index. The height of the plant also had a significant effect on the model.

The desired goal is to develop a universal agricultural spray retention model that has only a few, simple parameters. A model by Grayson et al. (1991, 1993) was deemed the most appropriate to predict spray retention under laboratory track spraying conditions. The model is:

$\mathrm{V}_{\mathrm{s}, \mathrm{T}}=\mathrm{V}_{\mathrm{s}, \mathrm{wG}} \mathrm{M}_{\mathrm{T}}\left[\frac{\left(1+\operatorname{Cos} \theta_{W, T}\right)}{\left(1+\operatorname{Cos} \theta_{W, G}\right)}\right]+f \mathrm{M}_{\mathrm{T}}\left[1-\frac{(D S T) s}{73}\right] \times\left[1-\frac{\left(1+\operatorname{Cos} \theta_{W, T}\right)}{\left(1+\operatorname{Cos} \theta_{W, G}\right)}\right]$

where $\mathrm{V}_{\mathrm{S}, \mathrm{T}}=$ the volume of spray deposited on any target, $\mathrm{T}$, by any solution, $\mathrm{S}$; $\mathrm{V}_{\mathrm{S}}$,WG $=$ the volume of spray deposited on watchglass $\mathrm{WG}$ by solution $\mathrm{S} ; \mathrm{M}_{\mathrm{T}}=$ morphology coefficient for the target, T; $\operatorname{Cos} \theta_{\mathrm{W}, \mathrm{T}}=$ contact angle of water on the target, $\mathrm{T}$; $\operatorname{Cos} \theta_{\mathrm{W}, \mathrm{G}}=$ contact angle of water on the watchglass surface; $(\mathrm{DST})_{\mathrm{S}}=$ dynamic surface tension of solution $\mathrm{S}$ at an appropriate surface age; $f=$ regression coefficient.

The objective of this study was to determine whether this model could predict retention accurately, needed further development or was inappropriate as a basis for a universal spray retention model. 


\section{MATERIALS AND METHODS}

Spray retention on outdoor-grown potted (Bloom potting mix, Yates, New Zealand) potato (Solanum tuberosum L. cv. Ilam Hardy) and onion (Allium cepa L. cv. Regular Long Keeper) plants was determined using a calibrated belt tracksprayer. Treatments were water, and water plus three concentrations of Silwet L-77 $(0.01 \%, 0.05 \%$ and $0.1 \%)$, chosen to provide a range of dynamic surface tensions ( 26 to $73 \mathrm{mN} / \mathrm{m}$ ). Tartrazine dye (10 g/litre) was incorporated into all treatments. Treatments were applied (20 replicate plants per treatment) at either (nominal) 200 or 500 litres/ha equivalent through a hollow cone nozzle (TXVS-6, $220 \mathrm{kPa}$ ) mounted $0.5 \mathrm{~m}$ above mean plant height. Application rates (spray deposition) were determined by spraying over plastic disks $\left(10 \mathrm{~cm}^{2}\right.$; 8 replicates per treatment) positioned at pot height and interspersed randomly amongst replicate plants. After spraying, onion and potato plants were harvested at ground level, washed immediately in a known volume of water to recover retained dye and their dry weights (DW) determined (Murray et al. 1998).

Surface areas of representative plants were measured to correlate DW with area (correlations for onion and potato were $\mathrm{R}^{2}=0.89$ and 0.85 , respectively). The potato and onion plants were approximately 40 and $30 \mathrm{~cm}$ in height respectively and the average calculated plant area was 666 and $108 \mathrm{~cm}^{2}$ respectively. Absorbance of each solution (washed plant or disk trap washings) was measured using a Pye Unicam UV/VIS spectrophotometer (tartrazine $\lambda=427 \mathrm{~nm}$ ) to determine total dye recovery, expressed as $\mu$ dye solution per $\mathrm{cm}^{2}$.

Droplets ( $2 \mu \mathrm{l} ; 20$ replicates) of water were applied to the adaxial surfaces of freshly detached potato and onion leaves, as well as the plastic disk material (used instead of a watchglass), to determine the contact angle. The contact angle was calculated from the projected image of the droplet (Fogg 1947). A bubble pressure tensiometer (Krüss BP2) was used to measure the dynamic surface tension of the solutions over a time span of 15 to 1000 milliseconds.

Analysis of variance and least significant difference tests (LSD) at the 5\% level were used to compare treatments. Stabilising transformations were performed where necessary prior to analysis.

\section{RESULTS AND DISCUSSION}

The addition of an adjuvant was generally of no benefit when spraying easy-to-wet plant species such as potato (Table 1), which is in agreement with existing literature (de Ruiter et al. 1990; Hall et al. 1997; Bruns \& Nalewaja 1998). There was little difference in percent retention between the two spray volumes studied. Easy to wet species have inherently high spray retention regardless of spray volume or droplet size (Knoche 1994). The addition of adjuvants can alter the spray characteristics, which will affect deposition. In the present study, the addition of Silwet L-77 significantly reduced spray deposition $\left(\mu \mathrm{l} / \mathrm{cm}^{2}\right)$ compared to water.

TABLE 1: Spray retention by potatoes.

\begin{tabular}{|c|c|c|c|c|}
\hline Treatment & $\begin{array}{c}\text { Nominal spray } \\
\text { volume } \\
\text { (litres/ha) } \\
\end{array}$ & $\begin{array}{c}\text { Actual spray deposition } \\
\text { (lid retention) } \\
(\text { litres } / \mathrm{ha})\left(\mu \mathrm{l} / \mathrm{cm}^{2}\right)\end{array}$ & $\begin{array}{l}\text { Actual retention } \\
\text { by potato plants }{ }^{1} \\
\left(\mu \mathrm{l} / \mathrm{cm}^{2}\right)\end{array}$ & $\begin{array}{l}\text { Retention }^{1} \\
(\%)\end{array}$ \\
\hline Water & 200 & $(176) 1.76^{\mathrm{d}}$ & $1.33^{\mathrm{d}}$ & $75.6^{b}$ \\
\hline Water & 500 & $(423) 4.23^{\mathrm{a}}$ & $2.94^{\mathrm{a}}$ & $69.5^{\mathrm{bc}}$ \\
\hline L-77 (0.01\%) & 200 & (114) $1.14^{\mathrm{e}}$ & $1.02^{\mathrm{e}}$ & $89.5^{\mathrm{a}}$ \\
\hline L-77 $(0.01 \%)$ & 500 & (282) $2.82^{\mathrm{b}}$ & $1.95^{\mathrm{b}}$ & $69.1^{\mathrm{bc}}$ \\
\hline L-77 (0.05\%) & 200 & $(94) \quad 0.94^{\mathrm{f}}$ & $0.69^{f}$ & $73.4^{\mathrm{bc}}$ \\
\hline L-77 (0.05\%) & 500 & (242) $2.42^{c}$ & $1.62^{\mathrm{c}}$ & $66.9^{c}$ \\
\hline L-77 $(0.1 \%)$ & 200 & (122) $1.22^{\mathrm{e}}$ & $0.97^{\mathrm{e}}$ & $79.5^{\mathrm{bc}}$ \\
\hline L-77 (0.1\%) & 500 & (249) $2.49^{c}$ & $1.67^{\mathrm{c}}$ & $67.1^{\mathrm{bc}}$ \\
\hline
\end{tabular}

${ }^{1}$ Treatments within columns with no letter in common are significantly different $(\mathrm{P}=0.05)$. 
The dynamic surface tension of water was 73 . Therefore, in calculating the volume of water retained, the second half of equation 1 is zero, and the equation reduces to:

$$
\mathrm{V}_{\mathrm{S}, \mathrm{T}}=\mathrm{V}_{\mathrm{s}, \mathrm{WG}} \mathrm{M}_{\mathrm{T}}\left[\frac{\left(1+\operatorname{Cos} \theta_{W, T}\right)}{\left(1+\operatorname{Cos} \theta_{W, G}\right)}\right]
$$

The contact angle of water on a potato leaf was determined as $61.6^{\circ}$ and $106.5^{\circ}$ on the plastic lids used to quantify total deposition. Using the actual results from spraying potatoes with water allows $\mathrm{M}_{\mathrm{T}}$, the plant morphology factor, to be calculated. The average $\mathrm{M}_{\mathrm{T}}$ for potato was calculated as 0.35 . Once $\mathrm{M}_{\mathrm{T}}$ for potato (for the growth stage studied) had been determined, this could be substituted in equation 1. The data for the spray solutions containing Silwet L-77 could then be used in order to determine $f$.

Table 2 shows the predicted retention on potato plants using the average calculated $f$ value $(-0.06085)$ for the entire data set. Predicted values are in good agreement with actual retention values. This was also the case when different $f$ values for the two spray volumes (data not shown) were used (Average of actual retention $=102.1 \%$, $\% \mathrm{CV}=9.6$ ). However, prediction of retention by easy to wet species, such as potatoes, need not be this complex, as there is an excellent linear relationship $\left(\mathrm{R}^{2}=0.99\right)$ between deposition (lid retention) and actual potato plant retention (Fig. 1).

TABLE 2: Predicted spray retention $\left(\mu \mathrm{l} / \mathrm{cm}^{2}\right)$ by potatoes using the average calculated $f$ value.

\begin{tabular}{|c|c|c|c|c|}
\hline \multirow[b]{2}{*}{ Treatment } & \multirow{2}{*}{$\begin{array}{c}\text { Nominal spray } \\
\text { volume (litres/ha) }\end{array}$} & \multicolumn{2}{|c|}{ Spray retention } & \multirow{2}{*}{$\begin{array}{l}\% \text { of } \\
\text { Actual }\end{array}$} \\
\hline & & Predicted & Actual $^{1}$ & \\
\hline Water & 200 & 1.27 & $1.33^{\mathrm{d}}$ & 95.4 \\
\hline Water & 500 & 3.05 & $2.94^{\mathrm{a}}$ & 103.7 \\
\hline L-77 (0.01\%) & 200 & 0.83 & $1.02^{\mathrm{e}}$ & 81.2 \\
\hline L-77 (0.01\%) & 500 & 2.04 & $1.95^{\mathrm{b}}$ & 104.6 \\
\hline L-77 (0.05\%) & 200 & 0.691 & $0.69^{f}$ & 100.2 \\
\hline L-77 (0.05\%) & 500 & 1.76 & $1.62^{\mathrm{c}}$ & 108.5 \\
\hline L-77 $(0.1 \%)$ & 200 & 0.894 & $0.97^{\mathrm{e}}$ & 92.1 \\
\hline L-77 (0.1\%) & 500 & 1.81 & $1.67^{\mathrm{c}}$ & 108.4 \\
\hline \multicolumn{4}{|c|}{ Mean (SD and \%CV) } & 99.3 (9.3 and $9.4 \%)$ \\
\hline
\end{tabular}

${ }^{1}$ Treatments within columns with no letter in common are significantly different $(\mathrm{P}=0.05)$.

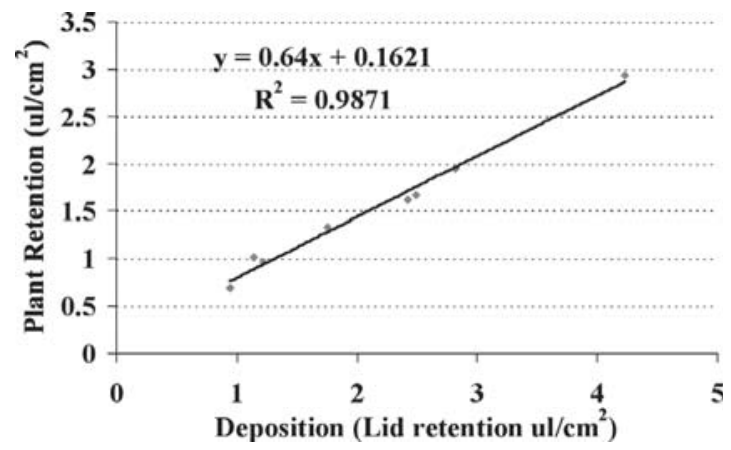

FIGURE 1: Spray deposition (lid retention) versus spray retention by potato plants. 
Percentage retention by onion foliage (Table 3) increased with increasing adjuvant concentration. This is in agreement with published literature (de Ruiter et al. 1990; Hall et al. 1997; Bruns \& Nalewaja 1998) stating that the addition of surfactants is beneficial in the case of difficult to wet species. The percentage retained was significantly higher for the lower spray volume (200 litres/ha) treatments except with water.

TABLE 3: Spray retention by onions.

\begin{tabular}{|c|c|c|c|c|c|}
\hline Treatment & $\begin{array}{c}\text { Nominal spray } \\
\text { volume } \\
\text { (litres/ha) }\end{array}$ & $\begin{array}{r}\text { Actual spra } \\
\text { (lid rete } \\
\text { (litres/ha) }\end{array}$ & $\begin{array}{l}\text { deposition } \\
\text { ation })^{1} \\
\left(\mu \mathrm{l} / \mathrm{cm}^{2}\right)\end{array}$ & $\begin{array}{l}\text { Actual retention } \\
\text { by onion plants } \\
\left(\mu \mathrm{l} / \mathrm{cm}^{2}\right)\end{array}$ & $\begin{array}{l}\text { Retention }^{1} \\
\quad(\%)\end{array}$ \\
\hline Water & 200 & (190) & $1.90^{\mathrm{d}}$ & $0.322^{\mathrm{d}}$ & $16.9^{f}$ \\
\hline Water & 500 & (441) & $4.41^{\mathrm{a}}$ & $0.815^{\mathrm{c}}$ & $18.5^{\mathrm{f}}$ \\
\hline L-77 (0.01\%) & 200 & (113) & $1.13^{\mathrm{e}}$ & $0.371^{\mathrm{d}}$ & $32.8^{\mathrm{d}}$ \\
\hline L-77 (0.01\%) & 500 & (267) & $2.67^{\mathrm{b}}$ & $0.689^{c}$ & $25.8^{\mathrm{e}}$ \\
\hline L-77 (0.05\%) & 200 & (79) & $0.79^{f}$ & $0.709^{c}$ & $89.7^{b}$ \\
\hline L-77 (0.05\%) & 500 & (233) & $2.33^{c}$ & $1.467^{\mathrm{a}}$ & $63.0^{c}$ \\
\hline L-77 $(0.1 \%)$ & 200 & (115) & $1.15^{\mathrm{e}}$ & $1.215^{\mathrm{b}}$ & $105.7^{\mathrm{a}}$ \\
\hline L-77 $(0.1 \%)$ & 500 & $(240)$ & $2.40^{c}$ & $1.554^{\mathrm{a}}$ & $64.8^{\mathrm{c}}$ \\
\hline
\end{tabular}

${ }^{1}$ Treatments within columns with no letter in common are significantly different $(\mathrm{P}=0.05)$.

The contact angle for water on onion was $180^{\circ}$ (total repulsion). This would have made the entire equation (1) zero, so a contact angle of $179^{\circ}$ was used. The plant morphology factor for the onions was calculated to be 846 . Table 4 shows the predicted retention by onion plants using the average calculated $f$ value $(0.001476)$ for the entire data set. Using different $f$ values for the two spray volumes (data not shown) the average percent of actual versus predicted retention was $102(\% \mathrm{CV}=23)$. There was no simple relationship between lid retention (i.e. deposition) and spray retention by onion $\left(\mathrm{R}^{2}=0.026\right)$.

TABLE 4: Predicted spray retention $\left(\mu \mathrm{l} / \mathrm{cm}^{2}\right)$ by onions using the average calculated $f$ value.

\begin{tabular}{|c|c|c|c|c|}
\hline \multirow[b]{2}{*}{ Treatment } & \multirow{2}{*}{$\begin{array}{c}\text { Nominal spray } \\
\text { volume (litres/ha) }\end{array}$} & \multicolumn{2}{|c|}{ Spray retention } & \multirow{2}{*}{$\begin{array}{l}\% \text { of } \\
\text { Actual }\end{array}$} \\
\hline & & Predicted & Actual $^{1}$ & \\
\hline Water & 200 & 0.342 & $0.322^{\mathrm{d}}$ & 106 \\
\hline Water & 500 & 0.794 & $0.815^{\mathrm{c}}$ & 97 \\
\hline L-77 (0.01\%) & 200 & 0.580 & $0.371^{\mathrm{d}}$ & 156 \\
\hline L-77 (0.01\%) & 500 & 0.857 & $0.689^{c}$ & 124 \\
\hline L-77 (0.05\%) & 200 & 0.878 & $0.709^{c}$ & 124 \\
\hline L-77 (0.05\%) & 500 & 1.155 & $1.467^{\mathrm{a}}$ & 79 \\
\hline L-77 $(0.1 \%)$ & 200 & 0.993 & $1.215^{\mathrm{b}}$ & 82 \\
\hline L-77 (0.1\%) & 500 & 1.219 & $1.554^{\mathrm{a}}$ & 78 \\
\hline \multicolumn{4}{|c|}{ Mean (SD and \%CV) } & $106(28$ and $26 \%)$ \\
\hline
\end{tabular}

${ }^{1}$ Treatments within columns with no letter in common are significantly different $(\mathrm{P}=0.05)$.

\section{CONCLUSIONS}

The model by Grayson et al. (1993) worked reasonably well in the current study. An average $f$ value for volume (200 and 500 litres/ha) was found to work well. However, different $f$ values are required for each plant species and plant age studied. The model should be able to predict the retention of a formulation that has not been previously 
studied, by a plant species (of a specific age) already studied (as well as for specific volumes and nozzles already studied). The only parameter that would need to be measured for the new formulation is dynamic surface tension. Deposition could be either measured or specified. However, to be a truly predictive model, the model needs extensive revision. For example, when using younger onions it was necessary to recalculate both the $f$ value and the morphology factor using the new data, in order to provide good prediction of retention (data not shown). A universal model needs to be developed in order to predict retention by plant species, of any age, not previously studied, using formulations, volumes and nozzles that have not been previously studied. To do this, $\mathrm{M}_{\mathrm{T}}$ needs to be related to real, measurable plant morphology factors (e.g. height, leaf area index) rather than estimated after doing an experiment. It may be more appropriate to use a $20 \%$ acetone contact angle (Forster \& Zabkiewicz 2001) to distinguish between plant surfaces. Prediction of whole plant retention by easy-to-wet plant species having relatively horizontal leaves should be much less complex than retention by difficult-to-wet species or species having relatively vertical leaves. However, differences due to different nozzles (i.e. droplet sizes) need to be investigated. Deposition may be sufficient to predict retention, for easy to wet plants with horizontal foliage. Furthermore, droplet size distribution may need to be included in the model and the $f$ value needs to be related to specific measurements.

\section{ACKNOWLEDGEMENTS}

The New Zealand Public Good Science Fund provided funding for this work. The authors would like to thank Rachel Murray and Linda Lester for technical assistance. Silwet L-77 ${ }^{\circledR}$ was supplied by OSi Specialties.

\section{REFERENCES}

Bache, D.H. 1979: Particle transport within plant canopies - I. A framework for analysis. Atmos. Environ. 13: 1257-1262.

Bache, D.H. 1985: Prediction and analysis of spray penetration into plant canopies. In: Application and Biology, BCPC Monograph No. 28. BCPC Publications, Farnham, Surrey. Pp. 183-190.

Bache, D.H.; Uk, S. 1975: Transport of aerial spray, II. Transport within a crop canopy. Agric. Meteorol. 15: 371-377.

Bruns, D.E.; Nalewaja, J.D. 1998: Spray retention is affected by spray parameters, species, and adjuvants. In: Nalewaja, J.D.; Goss, G.R.; Tann, R.S. ed. Pesticide Formulations and Application Systems: Eighteenth Volume, ASTM STP 1347. American Society for Testing and Materials. Pp. 107-119.

de Ruiter, H.; Uffing, A.J.M; Meinen, E.; Prins, A. 1990: Influence of surfactants and plant species on leaf retention of spray solutions. Weed Science 38: 567-572.

Fogg, G.E. 1947: Quantitative studies on the wetting of leaves by water. Proc. Royal Society London, Series B. 134:503-522.

Forster, W.A.; Zabkiewicz, J.A. 2001: Improved method for leaf surface roughness characterisation. In: de Ruiter H. ed. Proc. 6th Int. Symp. on Adjuvants for Agrochemicals, ISAA 2001 Foundation. Pp. 113-118.

Gyldenkærne, S.; Secher, B.J.M; Nordbo, E. 1999: Ground deposit of pesticides in relation to the cereal canopy and density. Pesticide Sci. 55: 1210-1216.

Grayson, B.T.; Webb, J.D.; Pack, S.E.; Edwards, D. 1991: Development and assessment of a mathematical model to predict foliar spray deposition under laboratory track spraying conditions. Pesticide Sci. 33: 281-304.

Grayson, B.T.; Pack, S.E.; Edwards, D.; Webb, J.D. 1993: Assessment of a mathematical model to predict spray deposition under laboratory track spraying conditions. II: Examination with further plant species and diluted formulations. Pesticide Sci. 37: 133-140. 
Hall, K.J.; Holloway, P.J.; Stock, D. 1997: Factors affecting the efficiency of spray delivery onto foliage using oil-based adjuvants. Aspects Appl. Biol. 48:113-120.

Knoche, M. 1994: Effect of droplet size and carrier volume on performance of foliageapplied herbicides. Crop Prot. 13(3):163-178.

Murray, R.J.; Gaskin, R.E.; Grassam, M.R. 1998: Evaluation of a novel adjuvant for use with glyphosate on perennial ryegrass. Proc. $51^{\text {st }}$ N.Z. Plant Prot. Conf.: 162-165. 